\title{
Circulating immune biomarkers as predictors of the response to pembrolizumab and weekly low dose carboplatin and paclitaxel in NSCLC and poor PS: An interim analysis
}

\author{
MARCELO BONOMI ${ }^{1}$, TAMJEED AHMED ${ }^{2}$, SAFOA ADDO $^{3}$, MITRA KOOSHKI $^{2}$, DARIO PALMIERI ${ }^{4}$, \\ BEVERLY J. LEVINE ${ }^{5}$, JIMMY RUIZ ${ }^{2}$, STEFAN GRANT ${ }^{2}$, WILLIAM J. PETTY ${ }^{2}$ and PIERRE L. TRIOZZI ${ }^{2}$ \\ ${ }^{1}$ Department of Medical Oncology, The Ohio State University, Columbus, OH 43210; \\ ${ }^{2}$ Wake Forest University Comprehensive Cancer Center; ${ }^{3}$ Department of Internal Medicine, Wake Forest Baptist \\ Medical Center, Winston-Salem, NC 27157; ${ }^{4}$ Solid Tumor Biology Program, Comprehensive Cancer Center, The Ohio \\ State University, Columbus, OH 43210; ${ }^{5}$ Division of Public Health Sciences, Wake Forest University Comprehensive \\ Cancer Center, Medical Center Blvd, Winston-Salem, NC 27157, USA
}

Received March 13, 2018; Accepted October 26, 2018

DOI: $10.3892 / \mathrm{ol} .2018 .9724$

\begin{abstract}
The combination of standard-dose chemotherapy and immunotherapy has been shown to be beneficial for patients with non-small cell lung cancer (NSCLC) with good performance status (PS). However, treatment options for patients with poor PS are limited. In the present study, the feasibility and immunological effects of low-dose chemotherapy with carboplatin and paclitaxel combined with immunotherapy with pembrolizumab were examined in patients with metastatic NSCLC and a poor PS. Patients with advanced NSCLC and a PS of 2 were randomized to single-agent pembrolizumab at $200 \mathrm{mg}$ every 3 weeks or pembrolizumab combined with weekly carboplatin area under the curve 1 and paclitaxel $25 \mathrm{mg} / \mathrm{m}^{2}$. Blood for circulating immune cell phenotyping, soluble program death ligand 1 (sPD-L1) and immune-modulatory microRNAs (miRNAs) was collected prior to treatment and at weeks 4 and 7. Ten patients were randomized to the combination arm and 10 to the single-agent arm. Therapy was well tolerated. Four patients discontinued carboplatin due to hypersensitivity reactions but continued pembrolizumab and paclitaxel treatments. Increases in activated $\mathrm{CD} 4^{+} \mathrm{T}$ cells and in immune-regulatory miRNA, and decreases in myeloid derived suppressor cells were observed in the blood of patients in the combination arm and not in the single-agent arm. Changes in circulating regulatory T cells and SPD-L1 were not observed. Seven patients in the combination arm manifested a partial response compared with only two in the single-agent arm. Weekly low-dose
\end{abstract}

Correspondence to: Dr Tamjeed Ahmed, Wake Forest University Comprehensive Cancer Center, Medical Center Boulevard, Winston-Salem, NC 27157, USA

E-mail: tahmed@wakehealth.edu

Key words: lung cancer, phase II trials, immune responses to cancer, immunotherapy, poor performance status, chemo-immunotherapy, microRNAs chemotherapy carboplatin and paclitaxel was well tolerated and immunologically active when combined with pembrolizumab in patients with advanced NSCLC and a PS of 2. This combination merits further study in this patient population.

\section{Introduction}

Most patients with advanced non-small cell lung cancer (NSCLC) are candidates for systemic therapy. Platinum-based doublet chemotherapy has been the cornerstone of first line treatment regimens with response rates of $30 \%$ (1). Immunotherapy with antibodies that target the programmed cell death protein 1 pathway (PD-1/PD-L1) are now approved in both the first- and second-line settings (2-4). Response rates of $\sim 20 \%$ have been observed; many of the responses have been durable. Cytotoxic chemotherapy can enhance immune responses through several mechanisms and have been effectively combined with immunotherapeutics. Several platinum-based combination chemotherapy regimens have been tested with the anti-PD-1 antibody, nivolumab, in patients with NSCLC (5). The combination of another anti-PD-1 antibody, pembrolizumab, with carboplatin and pemetrexed has recently been approved for the first-line treatment of metastatic non-squamous NSCLC. The approval was based on data from the KEYNOTE-021 trial in which the response rate with the combination was $55 \%$ compared to $29 \%$ in patients treated with chemotherapy alone (6).

One of the strongest predictors of response and survival in patients with advanced NSCLC is performance status (PS) (7). Although platinum-based combination chemotherapy has been shown to be beneficial for patients with a good PS, 0 or 1 , there is still debate regarding its efficacy for patients with a poor PS, 2 or worse (8). PS 2 patients account for up to $30 \%$ of patients with advanced NSCLC. In addition to poor responses and survival outcomes, many of the treatment options can cause substantial toxicity in this subset of patients which is why no regimen is accepted as the standard-of-care $(9,10)$. Accrual to most NSCLC clinical trials, including the PD-1-inhibitor-chemotherapy trials, has been limited to patients with PS 0 or 1 . The frequent 
administration of low doses of chemotherapy, referred to as metronomic chemotherapy, has been tested in patients with NSCLC with poor PS (11-16). Although these approaches have been shown to be active and well tolerated, patients with advanced NSCLC and poor PS represent a large unmet need for new treatment options.

Cancer patients with poor PS have been characterized by decreases in $\mathrm{T}$ cell function and increases in myeloid suppressor cells (MDSC) and T regulatory (Treg) cells, cells that suppress antitumor immunity (17). Platinum and taxane compounds have been shown to stimulate cytolytic $\mathrm{T}$ lymphocytes and to inhibit MDSC and Treg cells $(18,19)$. There is evidence that weekly low-dose carboplatin and paclitaxel produces superior antitumor immune responses, including $\mathrm{T}$ cell activation and MDSC and Treg cell inhibition, when compared with maximally tolerated dosing (20). We report the interim analysis of an ongoing study which examines the feasibility of using weekly low-dose carboplatin and paclitaxel with pembrolizumab in patients with advanced NSCLC and poor PS.

\section{Patients and methods}

Patients. Patients were enrolled to this clinical trial, which was reviewed and approved by the Wake Forest Health Sciences Institutional Review Board (Winston-Salem, NC, USA). All patients provided written informed consent before undergoing any study-related procedures or testing. Eligibility criteria included histologically confirmed NSCLC that was recurrent (progression after surgery or radiation or chemo-radiation treatment for loco-regional disease) or metastatic; ECOG PS of 2 or 3; age $>18$; and at least one measurable lesion as defined by Response Evaluation Criteria in Solid Tumors (RECIST) version 1.1 (21). Key exclusion criteria included more than two previous lines of systemic treatment; active, untreated central nervous system metastases requiring steroids; previous exposure to PD-1/PD-L1 inhibitors; history of pneumonitis; infection with $\mathrm{HIV}$ or hepatitis $\mathrm{B} / \mathrm{C}$; pregnancy; a requirement for immunosuppression or chronic steroids; and active infection on antibiotics, antifungals, or antivirals.

Study design and treatment. Patients were randomized to pembrolizumab alone or pembrolizumab combined with weekly carboplatin and paclitaxel. The dosing for pembrolizumab was the same in both arms, $200 \mathrm{mg}$ intravenously over 30 min every 3 weeks. Carboplatin and paclitaxel were administered every 7 days at an AUC 1 (Calvert formula) intravenously over $1 \mathrm{~h}$ and $25 \mathrm{mg} / \mathrm{m}^{2}$ intravenously over $1 \mathrm{~h}$, respectively. Standard-of-care dosing adjustments were used. Treatment continued until unacceptable toxicity or disease progression. Three weeks of treatment were considered to be one cycle. This study is registered with NCI (NCT02581943).

Study assessments. Baseline assessments included a complete medical history, physical exam, electrocardiogram, complete blood count (CBC), comprehensive metabolic panel (CMP), and a CT scan of the chest and abdomen. A physical exam was performed every three weeks in all patients. Weekly CBC and CMP were obtained prior to each chemotherapy infusion for patients receiving the combination of low-dose chemotherapy and pembrolizumab and every three weeks for patients receiving pembrolizumab alone. Thyroid function studies were obtained every six weeks. Adverse events were characterized and graded using Common Terminology Criteria for Adverse Events version 4.0. The causal relationship (related or not related) between treatment and adverse events was determined by the investigator. Tumor response was assessed by CT scan at 7 weeks of initiation of therapy and every 12 weeks thereafter. In case of clinical suspicion of tumor progression, CT scans were obtained at a shorter interval. Complete response (CR) partial response (PR) and stable disease (SD) and progressive disease (PD) were evaluated and assigned according to RECIST version 1.1. Patients who manifested a CR, PR, or SD were considered to have achieved disease control. All imaging assessments were reviewed by at least one investigator and one radiologist. Blood, for immune laboratory correlates was collected into heparin from each patient before the first dosing and at weeks 4 and 7 , after the completion of cycles 1 and 2 , respectively.

Flow cytometry. An aliquot of whole peripheral blood was evaluated by multicolor flow cytometry using a FACSCalibur flow cytometer (BD Biosciences, Mountain View, CA, USA). Immune cell populations were identified using phycoerythrin-labeled FoxP3 and HLA-DR, fluorescein-isothiocynate-labeled cluster of differentation (CD)4, CD14, and inducible costimulator (ICOS); and allophycocyanin-labeled CD8. All labeled antibodies were purchased from BD Biosciences with the exception of FoxP3, which was purchased from eBiosciences (San Diego, CA, USA). The percentage of populations of interest was determined using gate statistics. The absolute number of MDSCs was calculated as follows: (total white blood cell count (cells $/ \mu \mathrm{l}$ ) x percent MDSCs). Treg cell frequencies were calculated by normalization to total CD4 $\mathrm{T}$ cell numbers.

miRs. Total RNA was isolated from plasma using the miRNeasy Mini kit (Qiagen Inc., Valencia, CA, USA) according to the manufacturer's instructions. Reverse transcription reactions were performed using a TaqMan MicroRNA Reverse Transcription kit (Applied Biosystems; Thermo Fisher Scientific, Inc., Waltham, MA, USA) according to the manufacturer's instructions. Reverse transcription-quantitative polymerase chain reaction (RT-qPCR) was performed using the reverse transcription reaction product, TaqMan MicroRNA Assay kit, and TaqMan Universal PCR Master Mix (Applied Biosystems; Thermo Fisher Scientific, Inc.) according to the manufacturer's instructions. TaqMan MicroRNA Assay kits for human miRs were used. Reactions were loaded onto a 96-well plate and run in duplicate on an ABI 7500 Fast Real-Time PCR System (Applied Biosystems; Thermo Fisher Scientific, Inc.). The reactions were incubated at $50^{\circ} \mathrm{C}$ for $20 \mathrm{sec}$ and $95^{\circ} \mathrm{C}$ for $10 \mathrm{~min}$, followed by 40 cycles of denaturation at $95^{\circ} \mathrm{C}$ for $15 \mathrm{sec}$, then $1 \mathrm{~min}$ of annealing/extension at $60^{\circ} \mathrm{C}$. The $\Delta \Delta \mathrm{Cq}$ method was used to determine relative number of copies (RQ) of miR (22). Data were normalized to a $C$. elegans synthetic miR sequence, cel-miR-39 (Qiagen, Inc.), which was spiked in as a control during RNA isolation.

Soluble PD-L1. Plasma levels of soluble PD-L1 (sPD-L1) were determined by an ELISA kit (MyBioSource, San Diego, CA, USA) as recommended by the manufacturer. 
Table I. Patient characteristics.

\begin{tabular}{lcc}
\hline Treatment arm & Pembrolizumab + low-dosechemotherapy $(\mathrm{n}=10)$ & Pembrolizumab $(\mathrm{n}=10)$ \\
\hline Sex $(\mathrm{M} / \mathrm{F})$ & $5 / 5$ & $7 / 3$ \\
Mean age, years (range) & $67.9(56-85)$ & $68.6(54-83)$ \\
Histology, n (\%) & & $6(60)$ \\
Non-squamous & $8(80)$ & $4(40)$ \\
Squamous & $0(0)$ & $0(0)$ \\
Not otherwise specified & $2(20)$ & $6(60)$ \\
Prior treatment, n $(\%)$ & $7(70)$ & $4(40)$ \\
None & $3(30)$ & \\
Chemotherapy & & \\
\hline
\end{tabular}

$\mathrm{M} / \mathrm{F}$, male/female.

Statistical analysis. Data were summarized as percentages, means and standard deviation, or medians and ranges. Repeated-measures ANOVA (using PROC MIXED in SAS), considering treatment group (single vs. combination) and time period (pre-treatment, cycle 1, and cycle 2) as categorical (class) variables, as well as the treatment*time period interaction, were used to model levels of immune cells and factors and circulating miRs. We used post-hoc contrast statements on estimated least-squares means to compare the two treatment groups at specific time points, and to compare first and last time point measures within treatment group. A significant treatment time interaction in a model means that the null hypothesis that the two treatment groups have similar biomarker patterns over the 3 time points can be rejected. For each outcome variable we also conducted a planned contrast comparing differences in estimated least squares means at cycle 2 compared to pretreatment levels within each treatment group separately (i.e., 2 contrasts per outcome variable). The null hypothesis being tested in these contrasts is that the difference between pretreatment and cycle 2 levels within a treatment group is zero. We applied a Bonferroni correction within each model to the two P-values obtained from the contrast statements. A two-sided alpha of 0.05 was used to evaluate main and interactive model effects, and a two-sided alpha of 0.025 was used for the contrast statements, per the Bonferroni method of adjusting for the two extra contrasts within each model. All statistical analyses were performed using SAS version 9.4 (SAS Institute, Inc., Cary, NC, USA) and StatXact version 10 (Cytel Inc., Cambridge, MA, USA). All tests were two-sided, and $\mathrm{P}<0.05$ was considered to indicate a statistically significant difference.

\section{Results}

Clinical efficacy. All patients enrolled had a PS of 2. Ten were randomized to the pembrolizumab alone, the single-agent arm, and 10 to pembrolizumab, carboplatin, and paclitaxel, the combination arm. Patient characteristics are outlined in Table I. The mean number of 3-week cycles per patient was 7 (range, 2-14) in the single-agent arm and 9 (range, 4-16) in the combination arm. Adverse events are displayed in Table II.
One patient in the single-agent arm discontinued treatment due to $\mathrm{A}-\mathrm{V}$ block that was not considered related to treatment and that was successfully managed with pacemaker insertion. Two patients in the single-agent arm required replacement therapy due to treatment-induced hypothyroidism. One patient in the combination arm discontinued therapy due to Grade 3 fatigue. Four patients in the combination arm discontinued carboplatin due to allergic reactions at 3, 7, 9, and 10 months of treatment. The patient who had a reaction during the third month of treatment had received carboplatin prior. These patients were able to continue treatment with pembolizumab and weekly paclitaxel. One patient in the combination arm required replacement therapy due to treatment-induced hypothyroidism. Paclitaxel infusion reactions were not observed nor were pneumonitis or renal failure. Grade 4 and 5 adverse events were also not observed. Tumor response and disease control rates are summarized in Table III.

Immunologic effects. Circulating immune cells and soluble factors previously reported to be modulated by platinum and taxane chemotherapeutics and/or by PD-1 blockade were examined. Circulating CD14 ${ }^{+} \mathrm{HLA}_{-}-\mathrm{DR}^{-/ \text {low }}$ MDSC, which have been associated with therapeutic resistance in patients with NSCLC, were examined (23) Decreases in absolute numbers of this MDSC subpopulation were observed in the combination arm; significant changes were not observed in the single-agent arm (Fig. 1A). Significant changes in circulating $\mathrm{CD}^{+}{ }^{+} \mathrm{FOXP} 3^{+}$Treg cells were not observed in either arm (Fig. 1B). Expression of ICOS, a T cell costimulatory receptor related to $\mathrm{CD} 28$ expressed on activated $\mathrm{T}$ cells that has been associated clinical response in patients with NSCLC treated with PD-1 pathway blockade, was also examined (24). Increases in $\mathrm{ICOS}^{+} \mathrm{CD}^{+}$cell were observed in the combination arm but not in the single-agent arm (Fig. 1C). Significant changes in $\mathrm{ICOS}^{+} \mathrm{CD} 4^{+}$cells were not observed. Significant changes in circulating sPD-L1, which has been associated with immune suppression and clinical outcome, were also not observed (Fig. 2A) (25-28). Pre-treatment sPD-L1 levels tended to be higher in patients that manifested PD $(346 \pm 85 \mathrm{pg} / \mathrm{ml}$, $\mathrm{n}=5)$, compared to patients that manifested PR $(272 \pm 70 \mathrm{pg} / \mathrm{ml}$, $\mathrm{n}=8$ ), but this difference was not statistically significant. 
Table II. Adverse events.

\begin{tabular}{|c|c|c|c|c|}
\hline \multirow[b]{2}{*}{ Event type } & \multicolumn{2}{|c|}{$\begin{array}{l}\text { Pembrolizumab + low-dose } \\
\text { chemotherapy }(\mathrm{n}=10)\end{array}$} & \multicolumn{2}{|c|}{ Pembrolizumab $(\mathrm{n}=10)$} \\
\hline & Grade $1-2$ & Grade 3 & Grade $1-2$ & Grade 3 \\
\hline Any event & 28 & 0 & 16 & 1 \\
\hline Alopecia & 0 & 0 & 0 & 0 \\
\hline Anemia & 1 & 0 & 0 & 0 \\
\hline Anorexia & 2 & 0 & 1 & 0 \\
\hline Arthralgia & 1 & 0 & 1 & 0 \\
\hline Constipation & 0 & 0 & 0 & 0 \\
\hline Cough & 0 & 0 & 2 & 0 \\
\hline Diarrhea & 1 & 0 & 2 & 0 \\
\hline Dizziness & 0 & 0 & 0 & 0 \\
\hline Dry skin & 1 & 0 & 1 & 0 \\
\hline Dysgeusia & 0 & 0 & 0 & 0 \\
\hline Epistaxis & 0 & 0 & 0 & 0 \\
\hline Fatigue & 2 & 0 & 1 & 1 \\
\hline Headache & 1 & 0 & 1 & 0 \\
\hline Hypersensitivity & 3 & 0 & 0 & 0 \\
\hline Hypoesthesia & 0 & 0 & 0 & 0 \\
\hline Hypomagnesemia & 0 & 0 & 0 & 0 \\
\hline Hypothyroidism & 1 & 0 & 2 & 0 \\
\hline Influenza-like illness & 0 & 0 & 0 & 0 \\
\hline Infusion reactions & 0 & 0 & 0 & 0 \\
\hline Leukopenia & 2 & 0 & 0 & 0 \\
\hline Lymphopenia & 2 & 0 & 0 & 0 \\
\hline Mucositis & 0 & 0 & 0 & 0 \\
\hline Musculoskeletal pain & 2 & 0 & 0 & 0 \\
\hline Nausea & 2 & 0 & 0 & 0 \\
\hline Neutropenia & 2 & 0 & 0 & 0 \\
\hline Peripheral neuropathy & 1 & 0 & 0 & 0 \\
\hline Pneumonitis & 1 & 0 & 2 & 0 \\
\hline Pruritus & 1 & 0 & 2 & 0 \\
\hline Pyrexia & 0 & 0 & 0 & 0 \\
\hline Rash & 1 & 0 & 1 & 0 \\
\hline Renal failure (acute) & 0 & 0 & 0 & 0 \\
\hline Thrombocytopenia & 1 & 0 & 0 & 0 \\
\hline Tinnitus & 0 & 0 & 0 & 0 \\
\hline Transaminase increase & 0 & 0 & 0 & 0 \\
\hline Vomiting & 0 & 0 & 0 & 0 \\
\hline
\end{tabular}

Circulating levels of specific miRs implicated in regulating antitumor immune responses were also examined (29). Prominent among these are miRs-146a, 155, 181a, 20a and 223, plasma levels of which have been associated with changes in immune effector and regulatory cells in cancer patients $(30,31)$. Enhanced immunity effected by taxanes has been associated with increases in miR-146a and $155(32,33)$. Increases in plasma levels of all the immune-regulatory miRs tested were observed with treatment in the combination arm; increases in miR-155, 181, and 223 were statistically significant (Fig. 2B).

\section{Discussion}

Patients who are able to care for themselves but are unable to perform work-related activities are considered to have a PS of 2 . These patients constitute a significant proportion of patients with NSCLC. Poor PS patients with NSCLC, irrespective of age, have poorer outcomes as well as an increased incidence of adverse events with therapy. The feasibility of applying weekly low-dose carboplatin and paclitaxel with pembrolizumab in this patient population was examined by randomizing patients to the combination or to pembrolizumab alone. Weekly 
Table III. Tumor response.

Treatment

Pembrolizumab + low-dose chemotherapy $(n=10)$

Pembrolizumab $(n=10)$

Complete response, n (\%)

Partial response, $\mathrm{n}(\%)$

Stable disease, n (\%)

Disease control, n (\%)

Progressive disease, $\mathrm{n}(\%)$
$0(0)$

7 (70)

2 (20)

9 (90)

1 (10)
$0(0)$

$4(40)$
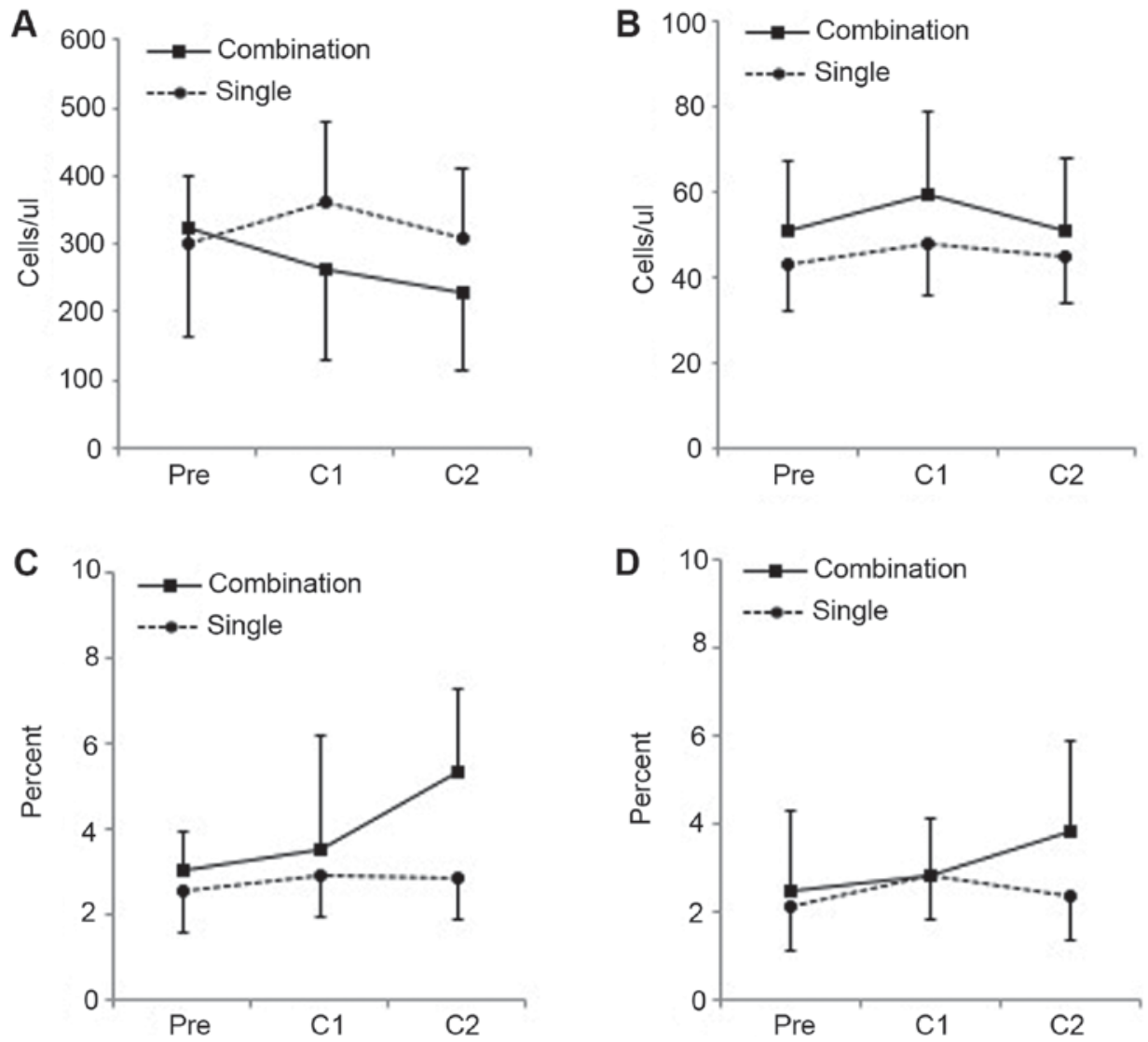

Figure 1. Circulating (A) CD14+Human Leukocyte Antigen-antigen D Related ${ }^{-/ 1 \text { ow }}$ myeloid suppressor cells, (B) $\mathrm{CD}^{+}{ }^{+}$Forkhead box $3^{+} \mathrm{T}$ regulatory cells and (C) $\mathrm{ICOS}^{+} \mathrm{CD}^{+}$and (D) $\mathrm{ICOS}^{+} \mathrm{CD} 8^{+}$cells prior to treatment (Pre group), and at the completion of cycle 1 (C1 group) and cycle 2 (C2 group) for patients treated with low-dose chemotherapy and pembrolizumab (combination, $\mathrm{n}=9$ ) or pembrolizumab alone (single, $\mathrm{n}=10$ ). Data are presented as the (unadjusted) mean \pm standard deviation. $\mathrm{CD}$, cluster of differentiation; ICOS, inducible costimulatory.
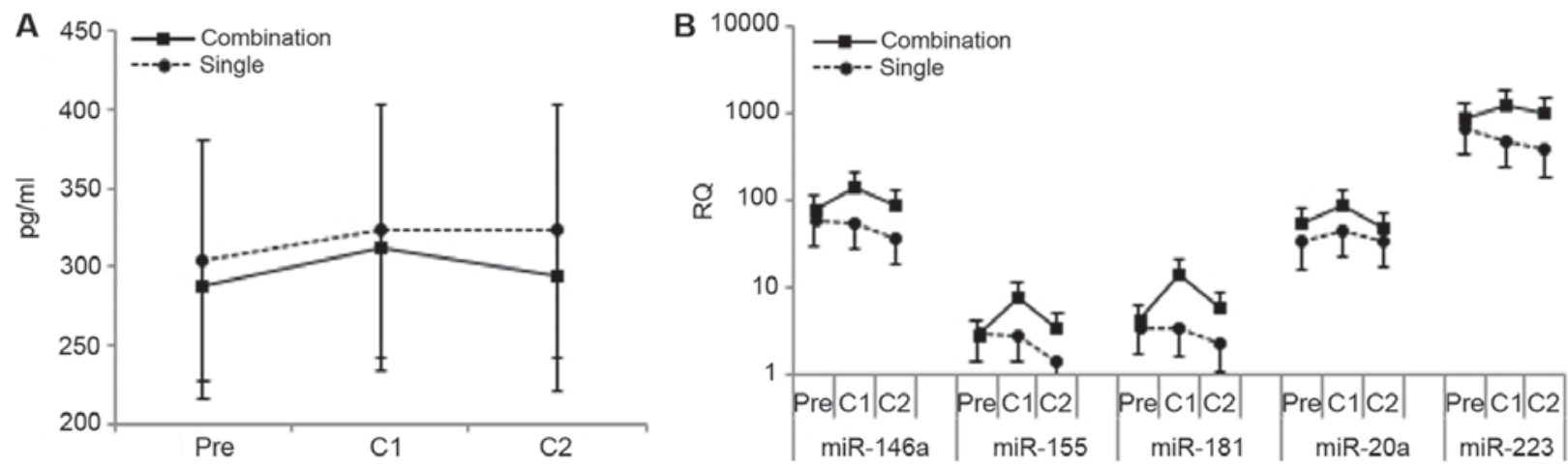

Figure 2. Circulating (A) soluble program death ligand 1 and (B) immune regulatory miRs prior to treatment (Pre group), and at the completion of cycle 1 (C1 group) and cycle 2 (C2 group) for patients treated with low-dose chemotherapy and pembrolizumab (combination, n=9) or pembrolizumab alone (single, $\mathrm{n}=10$ ). Data are presented as the (unadjusted) mean \pm standard deviation. miR, microRNA; RQ, relative number of copies. 
carboplatin, at AUC 3 or 2, and paclitaxel, at 75 or $100 \mathrm{mg} / \mathrm{m}^{2}$, respectively, has resulted in acceptable toxicity and response rates in patients with advanced NSCLC, including those with poor PS $(34,35)$. Immune activation was demonstrated in patients with ovarian cancer with weekly carboplatin at AUC 2 and paclitaxel at 60 to $80 \mathrm{mg} / \mathrm{m}^{2}$ (20). Because of potentially superior immune effects, we examined lower dosing, carboplatin at AUC 1 and paclitaxel at $25 \mathrm{mg} / \mathrm{m}^{2}$. We found that administering this chemotherapy-immunotherapy regimen to patients with advanced NSCLC and PS 2 was well tolerated and immunologically and clinically active.

Treatments in both the combination and single-agent arms were well tolerated. The incidences of Grade 3 adverse events were low. Carboplatin hypersensitivity was observed in 4 of the 10patientstreated with the combination. Repeatedexposureisthe most important predictive factor for platinum hypersensitivity, and the patients who did manifest hypersensitivity did receive more than 6 months of repeated exposures (36). How PD-1 blockade may influence platinum hypersensitivity, which is mediated primarily by IgE and/or mast cells/basophils, is not known. The toxicity observed compares favorably with other chemotherapy-PD-1 inhibitor combinations tested in advanced NSCLC patients with good PS. In a study of two doses of nivolumab combined with standard-dose, platinum-based doublet chemotherapy, Grade 3 or 4 treatment-related adverse events led to discontinuation in eight (14\%) of 56 patients, most commonly pneumonitis and acute renal failure (5). These included four of 14 patients in the $5 \mathrm{mg} / \mathrm{kg}$ nivolumab plus carboplatin-paclitaxel arm and two of 15 patients in the $10 \mathrm{mg} / \mathrm{kg}$ nivolumab plus carboplatin-paclitaxel arm. Hypersensitivity reactions occurred in $14(25 \%)$ of patients, all of whom received $10 \mathrm{mg} / \mathrm{kg}$ nivolumab, including six of 15 administered carboplatin-paclitaxel, seven of 15 administered cisplatin-pemetrexed, and one of 12 administered cisplatin-gemcitabine. In KEYNOTE-21, which involved 123 patients, the incidence of Grade 3 or worse adverse events was $39 \%$ patients in the pembrolizumab, carboplatin, and pemetrexed group and 26\% in the chemotherapy alone group. Infusion reactions were observed in only one (2\%) of 59 in the pembrolizumab plus chemotherapy group vs. none in the chemotherapy alone group (6).

Circulating cell regulators of the immune effects of chemotherapy and PD-1 inhibitors were examined.Decreases in MDSC were observed in the combination arm; changes in Treg cells were not. That $\mathrm{T}$ cells were activated in the combination arm was supported by the increase in ICOS expression on $\mathrm{CD} 4^{+}$cells. Although these findings are statistically non-significant after applying the Bonferroni correction, given the small sample size, we consider the results to be mainly hypothesis generating and warrant further study in a larger group of patients. Increased expression was not observed on $\mathrm{CD} 8^{+}$cells and not in the single-agent arm. ICOS expression was reported to increase on $\mathrm{CD}^{+}$cells of patients with NSCLC responding to single-agent PD-1 or PD-L1 blocking antibodies (22). Increases in $\mathrm{CD}^{+}$ICOS have been associated with response to the anti-CTLA-4 antibody, ipilimumab, in patients with melanoma (37). Significant changes in circulating immune suppressor and effector cells were not observed in the single-agent arm. It has been noted that whereas changes in MDSC have been evident intratumorally in patients treated with PD-1 inhibitors, changes in peripheral blood MDSC have not (38). In patients with melanoma treated with nivolumab combined with a vaccine, a decline in circulating Treg cells during treatment was associated with clinical benefit (39).

Circulating soluble immune regulators were also examined. Levels of SPD-L1 have had predictive value in patients with melanoma treated with CTLA-4 or PD-1 blockade (24). High plasma levels of SPD-L1 have been associated with reduced survival in lung cancer $(25,26)$. Although there is evidence that high baseline sPD-L1 is associated with disease progression, it remains unclear whether SPD-L1 levels are associated with clinical response to PD-1 blockade in patients with NSCLC (27). Patients in our study who manifested PD tended to have higher levels of SPD-L1 than patients who manifested PR, but differences were not statistically significant. Plasma miRs are emerging as a new class of biomarkers. Circulating levels of many miRs with immune-regulatory effects have demonstrated diagnostic or prognostic potential in NCSLC, including the miRs tested, miR-146a, 155, 181a, 20a, and 223 (40-45). As noted, enhanced immunity effected by taxanes in mice has been associated with increases in miR-146a and miR-155 $(31,32)$. Cisplatin has been shown to increase miR-146a and to decrease miR-181a (46-49). Increases in plasma levels of miR-155, 181a and 223 were associated with disease control the combination arm. miR-155 and miR-223 are involved in the development of MDSC as are miR-146a and miR-20a (50-53). miR-155 and 181a are involved in T cell regulation (54). miRs with immune regulatory activities also regulate a variety of other cellular processes. Of note, miR-181a and miR-20a has been implicated in regulating the sensitivity of tumor cells to platinums and taxanes (55-58).

A variety of factors are involved in the poor systemic therapy response rates observed in patients with NSCLC with poor PS $(9,10)$. Although this clinical trial was not designed to establish or compare response rates, 7 of 10 patients (70\%) in the combination arm manifested a PR compared to 2 of 10 patients $(20 \%)$ in the single-agent arm. Weekly low-dose carboplatin at AUC 1 and paclitaxel at $25 \mathrm{mg} / \mathrm{m}^{2}$ can be safely administered with pembrolizumab at standard dosing to patients with advanced NSCLC and poor PS. This regimen is immunologically active. Reductions in MDSC, increases in activated $\mathrm{CD}^{+} \mathrm{T}$ cells, and changes in immune-regulatory miRs are observed. The combination of this low-dose chemotherapy regimen and pembrolizumab is also clinically active and merits further study in this patient population.

\section{Acknowledgements}

Not applicable.

\section{Funding}

The present study was funded by Merck \& Co. as a part of an investigator initiated clinical trial (Merck Investigator Studies Program grant no. 52346).

\section{Availability of data and materials}

All data generated or analyzed during this study are included in this published article. 


\section{Authors' contributions}

MB, TA and PLT made substantial contributions to the conception and design of the study, interpreted the data, were involved in the drafting and revising of the manuscript critically for important intellectual content and gave final approval of the version to be published. BJL and WJP interpreted the data, assisting the drafting and revising of the manuscript critically for important intellectual content, and gave final approval of the version to be published. SA, MK, SG, JR and DP interpreted the data and critically revised the manuscript for important intellectual content.

\section{Ethics approval and consent to participate}

The present study was approved by Wake Forest Health Sciences Institutional Review Board (Clinical Trial Identifier, NCT02581943; Date of registration, 5/1/16). All patients provided written informed consent before undergoing any study-related procedures or testing.

\section{Patient consent for publication}

Not applicable.

\section{Competing interests}

The authors declare they have no competing interests.

\section{References}

1. Azzoli CG, Temin S, Aliff T, Baker S Jr, Brahmer J, Johnson DH, Laskin JL, Masters G, Milton D, Nordquist L, et al: 2011 focused update of 2009 American society of clinical oncology clinical practice guideline update on chemotherapy for stage IV non-small-cell lung cancer. J Clin Oncol 29: 3825-3831, 2011.

2. Reck M, Rodríguez-Abreu D, Robinson AG, Hui R, Csôszi T, Fülöp A, Gottfried M, Peled N, Tafreshi A, Cuffe S, et al: Pembrolizumab versus Chemotherapy for PD-L1-positive non-small-cell lung cancer. N Engl J Med 375: 1823-1833, 2016.

3. Brahmer J, Reckamp KL, Baas P, Crinò L, Eberhardt WE, Poddubskaya E, Antonia S, Pluzanski A, Vokes EE Holgado E, et al: Nivolumab versus docetaxel in advanced squamous-cell non-small-cell lung cancer. N Engl J Med 373: $123-135,2015$.

4. Rittmeyer A, Barlesi F, Waterkamp D, Park K, Ciardiello F, von Pawel J, Gadgeel SM, Hida T, Kowalski DM, Dols MC, et al: Atezolizumab versus docetaxel in patients with previously treated non-small-cell lung cancer (OAK): A phase 3, open-label, multicentre randomised controlled trial. Lancet 389: 255-265, 2017.

5. Rizvi NA, Hellmann MD, Brahmer JR, Juergens RA, Borghaei H, Gettinger S, Chow LQ, Gerber DE, Laurie SA, Goldman JW, et al: Nivolumab in combination with platinum-based doublet chemotherapy for first-line treatment of advanced non-small-cell lung cancer. J Clin Oncol 34: 2969-2979, 2016.

6. Langer CJ, Gadgeel SM, Borghaei H, Papadimitrakopoulou VA, Patnaik A, Powell SF, Gentzler RD, Martins RG, Stevenson JP, Jalal SI, et al: Carboplatin and pemetrexed with or without pembrolizumab for advanced, non-squamous non-small-cell lung cancer: A randomised, phase 2 cohort of the open-label KEYNOTE-021 study. Lancet Oncol 17: 1497-1508, 2016.

7. Sculier JP, Chansky K, Crowley JJ, Van Meerbeeck J and Goldstraw P; International Staging Committee and Participating Institutions: The impact of additional prognostic factors on survival and their relationship with the anatomical extent of disease expressed by the 6th edition of the TNM classification of malignant tumors and the proposals for the 7 th edition. J Thorac Oncol 3: 457-466, 2008.

8. Bunn PA Jr: Chemotherapy for advanced non-small-cell lung cancer: Who, what, when, why? J Clin Oncol 20 (18 Suppl): 23S-33S, 2002.
9. Tartarone A and Aieta M: Treatment of performance status 2 patients with advanced non-small-cell lung cancer: What we know and what we don't know. Future Oncol 5: 837-841, 2009.

10. Lilenbaum RC, Cashy J, Hensing TA, Young S and Cella D: Prevalence of poor performance status in lung cancer patients: Implications for research. J Thorac Oncol 3: 125-129, 2008.

11. Correale P, Cerretani D, Remondo C, Martellucci I, Marsili S, La Placa M, Sciandivasci A, Paolelli L, Pascucci A, Rossi M, et al: A novel metronomic chemotherapy regimen of weekly platinum and daily oral etoposide in high-risk non-small cell lung cancer patients. Oncol Rep 16: 133-140, 2006.

12. Bilir C, Durak S, Kizılkaya B, Hacıbekiroglu I, Nayır E and Engin $\mathrm{H}$ : Efficacy of metronomic vinorelbine in elderly patients with advanced non-small-cell lung cancer and poor performance status. Curr Oncol 24: e199-e204, 2017.

13. Zwitter M, Kovac V, Rajer M, Vrankar M and Smrdel U: Two schedules of chemotherapy for patients with non-small cell lung cancer in poor performance status: A phase II randomized trial. Anticancer Drugs 21: 662-668, 2010.

14. Lee KW, Lim JH, Kim JH, Lee CT and Lee JS: Weekly low-dose docetaxel for salvage chemotherapy in pretreated elderly or poor performance status patients with non-small cell lung cancer. J Korean Med Sci 23: 992-998, 2008.

15. Juan O, Albert A, Ordoño F, Casany R, Carañana V, Campos JM and Alberola V: Low-dose weekly paclitaxel as second-line treatment for advanced non-small cell lung cancer: A phase II study. Jpn J Clin Oncol 32: 449-454, 2002.

16. Hainsworth JD, Burris HA III and Greco FA: Weekly docetaxel as a single agent and in combination with gemcitabine in elderly and poor performance status patients with advanced non-small cell lung cancer. Semin Oncol 28 (3 Suppl 9): S21-S25, 2001.

17. Santegoets SJ, Welters MJ and van der Burg SH: Monitoring of the immune dysfunction in cancer patients. Vaccines (Basel) 4: pii: E29, 2016.

18. de Biasi AR, Villena-Vargas J and Adusumilli PS: Cisplatin-induced antitumor immunomodulation: A review of preclinical and clinical evidence. Clin Cancer Res 20: 5384-5391, 2014.

19. Javeed A, Ashraf M, Riaz A, Ghafoor A, Afzal S and Mukhtar MM: Paclitaxel and immune system. Eur J Pharm Sci 38: 283-290, 2009.

20. Chang CL, Hsu YT, Wu CC, Lai YZ, Wang C, Yang YC, Wu TC and Hung CF: Dose-dense chemotherapy improves mechanisms of antitumor immune response. Cancer Res 73: 119-127, 2013.

21. Eisenhauer EA, Therasse P, Bogaerts J, Schwartz LH, Sargent D, Ford R, Dancey J, Arbuck S, Gwyther S, Mooney M, et al: New response evaluation criteria in solid tumours: revised RECIST guideline (version 1.1). Eur J Cancer 45: 228-47, 2009.

22. Livak KJ and Schmittgen TD: Analysis of relative gene expression data using real-time quantitative PCR and the 2(-Delta Delta C(T)) method. Methods 25: 402-408, 2001.

23. Huang A, Zhang B, Wang B, ZAhang F, Fan KX and Guo YJ: Increased CD14(+)HLA-DR (-/low) myeloid-derived suppressor cells correlate with extrathoracic metastasis and poor response to chemotherapy in non-small cell lung cancer patients. Cancer Immunol Immunother 62: 1439-1451, 2013.

24. Kamphorst AO, Pillai RN, Yang S, Nasti TH, Akondy RS, Wieland A, Sica GL, Yu K, Koenig L, Patel NT, et al: Proliferation of PD-1+ CD8 T cells in peripheral blood after PD-1-targeted therapy in lung cancer patients. Proc Natl Acad Sci USA 114: 4993-4998, 2017.

25. Zhou J, Mahoney KM, Giobbie-Hurder A, Zhao F, Lee S, Liao X, Rodig S, Li J, Wu X, Butterfield LH, et al: Soluble PD-L1 as a biomarker in malignant melanoma treated with checkpoint blockade. Cancer Immunol Res 5: 480-492, 2017.

26. Okuma Y, Hosomi Y, Nakahara Y, Watanabe K, Sagawa Y and Homma S: High plasma levels of soluble programmed cell death ligand 1 are prognostic for reduced survival in advanced lung cancer. Lung Cancer 104: 1-6, 2017.

27. Zhang J, Gao J, Li Y, Nie J, Dai L, Hu W, Chen X, Han J, Ma X, Tian G, et al: Circulating PD-L1 in NSCLC patients and the correlation between the level of PD-L1 expression and the clinical characteristics. Thorac Cancer 6: 534-538, 2015.

28. Dronca RS, Mansfield AS, Liu X, Harrington S, Enninga EA, Kottschade LA, Koo CW, McWilliams RR, Block MS, Nevala WK, et al: Bim and soluble PD-L1 (sPD-L1) as predictive biomarkers of response to anti-PD-1 therapy in patients with melanoma and lung carcinoma. J Clin Oncol 35 (15 Suppl): S11534, 2017.

29. Paladini L, Fabris L, Bottai G, Raschioni C, Calin GA and Santarpia L: Targeting microRNAs as key modulators of tumor immune response. J Exp Clin Cancer Res 35: 103, 2016. 
30. Triozzi PL, Achberger S, Aldrich W, Elson P, Garcia J and Dreicer R: Differential immunologic and microRNA effects of 2 dosing regimens of recombinant human granulocyte/macrophage colony stimulating factor. J Immunother 35: 587-594, 2012.

31. Achberger S, Aldrich W, Tubbs R, Crabb JW, Singh AD and Triozzi PL: Circulating immune cell and microRNA in patients with uveal melanoma developing metastatic disease. Mol Immunol 58: 182-186, 2014.

32. Chen J, Yuan L, Fan Q, Su F, Chen Y and Hu S: Adjuvant effect of docetaxel on the immune responses to influenza A H1N1 vaccine in mice. BMC Immunol 13: 36, 2012.

33. Yuan L, Wu L, Chen J, Wu Q and Hu S: Paclitaxel acts as an adjuvant to promote both Th1 and Th2 immune responses induced by ovalbumin in mice. Vaccine 28: 4402-4410, 2010

34. Volk V, Cathomas R, Mark M, von Moos R, Klingbiel D, Brossart P and Mey U: Weekly carboplatin in combination with weekly paclitaxel in the treatment of metastatic non-small cell lung cancer: A single center 10-year experience. Support Care Cancer 24: 2119-2128, 2016.

35. Schuette W, Blankenburg T, Guschall W, Dittrich I, Schroeder M, Schweisfurth H, Chemaissani A, Schumann C, Dickgreber N, Appel $\mathrm{T}$ and Ukena D: Multicenter randomized trial for stage IIIB/IV non-small-cell lung cancer using every-3-week versus weekly paclitaxel/carboplatin. Clin Lung Cancer 7: 338-343, 2006

36. Caiado $\mathrm{J}$ and Castells $\mathrm{M}$ : Presentation and diagnosis of hypersensitivity to platinum drugs. Curr Allergy Asthma Rep 15: $15,2015$.

37. Carthon BC, Wolchok JD, Yuan J, Kamat A, Ng Tang DS, Sun J, $\mathrm{Ku}$ G, Troncoso P, Logothetis CJ, Allison JP and Sharma P Preoperative CTLA-4 blockade: Tolerability and immune monitoring in the setting of a presurgical clinical trial. Clin Cancer Res 16: 2861-2871, 2010.

38. Ribas A, Shin DS, Zaretsky J, Frederiksen J, Cornish A, Avramis E, Seja E, Kivork C, Siebert J, Kaplan-Lefko P, et al: PD-1 blockade expands intratumoral memory T cells. Cancer Immunol Res 4: 194-203, 2016.

39. Weber JS, Kudchadkar RR, Yu B, Gallenstein D, Horak CE, Inzunza HD, Zhao X, Martinez AJ, Wang W, Gibney G, et al: Safety, efficacy, and biomarkers of nivolumab with vaccine in ipilimumab-refractory or -naive melanoma. J Clin Oncol 31: 4311-4318, 2013

40. Heegaard NH, Schetter AJ, Welsh JA, Yoneda M, Bowman ED and Harris CC: Circulating micro-RNA expression profiles in early stage nonsmall cell lung cancer. Int J Cancer 130: $1378-2886,2012$

41. Shen J, Todd NW, Zhang H, Yu L, Lingxiao X, Mei Y, Guarnera M, Liao J, Chou A, Lu CL, et al: Plasma microRNAs as potential biomarkers for non-small-cell lung cancer. Lab Invest 91: 579-587, 2011.

42. Zheng D, Haddadin S, Wang Y, Gu LQ, Perry MC, Freter CE and Wang MX: Plasma microRNAs as novel biomarkers for early detection of lung cancer. Int J Clin Exp Pathol 4: 575-586, 2011.

43. Zhu W, He J, Chen D, Zhang B, Xu L, Ma H, Liu X, Zhang Y and Le H: Expression of miR-29c, miR-93, and miR-429 as potential biomarkers for detection of early stage non-small lung cancer. PLoS One 9: e87780, 2014.

44. Zhang H, Mao F, Shen T, Luo Q, Ding Z, Qian L and Huang J: Plasma miR-145, miR-20a, miR-21 and miR-223 as novel biomarkers for screening early-stage non-small cell lung cancer. Oncol Lett 13: 669-676, 2017.
45. Wu C, Cao Y, He Z, He J, Hu C, Duan H and Jiang J: Serum levels of miR-19b and miR-146a as prognostic biomarkers for non-small cell lung cancer. Tohoku J Exp Med 232: 85-95, 2014.

46. Zhou M, Liu Z, Zhao Y, Ding Y, Liu H, Xi Y, Xiong W, Li G, Lu J, Fodstad O, Riker AI and Tan M: MicroRNA-125b confers the resistance of breast cancer cells to paclitaxel through suppression of pro-apoptotic Bcl-2 antagonist killer 1 (Bak1) expression. J Biol Chem 285: 21496-21507, 2010.

47. Kong F, Sun C, Wang Z, Han L, Weng D, Lu Y and Chen G: miR-125b confers resistance of ovarian cancer cells to cisplatin by targeting pro-apoptotic Bcl-2 antagonist killer 1. J Huazhong Univ Sci Technolog Med Sci 31: 543, 2011.

48. Liu M, Wang J, Huang H, Hou J, Zhang B and Wang A: miR-181a-Twist1 pathway in the chemoresistance of tongue squamous cell carcinoma. Biochem Biophys Res Commun 441: 364-370, 2013.

49. Pogribny IP, Filkowski JN, Tryndyak VP, Golubov A, Shpyleva SI and Kovalchuk O: Alterations of microRNAs and their targets are associated with acquired resistance of MCF-7 breast cancer cells to cisplatin. Int J Cancer 127: 1785-1794, 2010.

50. Boldin MP, Taganov KD, Rao DS, Yang L, Zhao JL, Kalwani M, Garcia-Flores Y, Luong M, Devrekanli A, Xu J, et al: miR-146a is a significant brake on autoimmunity, myeloproliferation, and cancer in mice. J Exp Med 208: 1189-1201, 2011.

51. Li L, Zhang J, Diao W, Wang D, Wei Y, Zhang CY and Zen K: MicroRNA-155 and MicroRNA-21 promote the expansion of functional myeloid-derived suppressor cells. J Immunol 192: 1034-1043, 2014

52. Zhang M, Liu Q, Mi S, Liang X, Zhang Z, Su X, Liu J, Chen Y, Wang M, Zhang Y, et al: Both miR-17-5p and miR-20a alleviate suppressive potential of myeloid-derived suppressor cellsby modulating STAT3 expression. J Immunol 186: 4716-4724, 2011.

53. Liu Q, Zhang M, Jiang X, Zhang Z, Dai L, Min S, Wu X, He Q, Liu J, Zhang Y, et al: miR-223 suppresses differentiation of tumor-induced $\mathrm{CD} 11 \mathrm{~b}^{+} \mathrm{Gr}^{+}$myeloid-derived suppressor cells from bone marrow cells. Int J Cancer 129: 2662-2673, 2011.

54. Dooley J, Linterman MA and Liston A: MicroRNA regulation of T-cell development. Immunol Rev 253: 53-64, 2013.

55. Galluzzi L, Morselli E, Vitale I, Kepp O, Senovilla L, Criollo A Servant N, Paccard C, Hupé P, Robert T, et al: miR-181a and miR-630 regulate cisplatin-induced cancer cell death. Cancer Res 70: 1793-1803, 2010.

56. Li H, Zhang P, Sun X, Sun Y, Shi C, Liu H and Liu X: MicroRNA-181a regulates epithelial-mesenchymal transition by targeting PTEN in drug-resistant lung adenocarcinoma cells. Int J Oncol 47: 1379-1392, 2015.

57. Zhu M, Zhou X, Du Y, Huang Z, Zhu J, Xu J, Cheng G, Shu Y, Liu P, Zhu W and Wang T: miR-20a induces cisplatin resistance of a human gastric cancer cell line via targeting CYLD. Mol Med Rep 14: 1742-1750, 2016.

58. Lin HM, Castillo L, Mahon KL, Chiam K, Lee BY, Nguyen Q, Boyer MJ, Stockler MR, Pavlakis N, Marx G, et al: Circulating microRNAs are associated with docetaxel chemotherapy outcome in castration-resistant prostate cancer. Br J Cancer 110: 2462-2471, 2014 